\title{
Modelling weed competition and yield losses to study the effect of omission of herbicides in winter wheat
}

\author{
L. A. P. LOTZ1, M. J. KROPFF² \& R. M. W. GROENEVELD ${ }^{1}$ \\ 1 Centre for Agrobiological Research, P.O. Box 14, NL 6700 AA Wageningen, Netherlands \\ 2 Department of Theoretical Production Ecology, Wageningen Agricultural University, \\ P.O. Box 430, NL 6700 AK Wageningen, Netherlands
}

Received 11 May 1990; accepted 13 August 1990

\begin{abstract}
Various experiments were carried out to study the effect of herbicide treatment on the yield of winter wheat. Omission of herbicide application caused a significantly lower crop yield only when the densities of certain weed species were extremely high in spring. A dynamic model simulating the competition for light and water between broad-leaved weeds and winter wheat was used to analyse these experimental results. The aim of this analysis was to assess the observed small effects of annual broad-leaved weeds on yield of winter wheat in terms of the relative emergence time and physiological and morphological characteristics of the weeds. Like the experiments, the simulations indicated that in the Netherlands weeds emerging in spring hardly affect crop yield. Weeds emerging in autumn, however, may reduce crop yield considerably if they grow as tall as winter wheat $(20 \%$ loss at a density of 100 plants per $\mathrm{m}^{2}$ ). The results are discussed in relation to characteristics of crop rotation systems that include root and tuber crops.
\end{abstract}

Keywords: winter wheat, weeds, competition, herbicides, simulation model, cropping systems

\section{Introduction}

Annual broad-leaved weeds in winter wheat can be controlled by herbicides applied before or after wheat emergence in autumn or in spring. Various experiments have been done in the United Kingdom to determine at which growth stage of winter wheat application of herbicides results in the best control of the weeds and the lowest losses of crop yield (Evans \& Harvey, 1978; Orson, 1980, 1982; Wilson 1982). Statistically significant yield responses to herbicide application occurred only in half or less of these trials. It was concluded that weed control in spring, at the pseudostem erect stage, was at least as effective as weed control in autumn.

In our study we quantitatively analysed the need for weed control measures in winter wheat, and their timing, using a dynamic simulation model based on physio- 
logical and morphogenetic processes (Spitters \& Aerts, 1983; Kropff 1988; Spitters, 1989). In various experiments we examined the effect of autumn and spring herbicide treatments on the yield of winter wheat and the biomass of surviving weeds. The model simulated the observed effects of weeds on yield of winter wheat from the relative emergence time, plant height and specific leaf area of weeds.

\section{Materials and methods}

\section{Field experiments}

Fourteen field experiments were conducted at various sites in the Netherlands on both clay and sandy soils, over four years (Table 1). The experiments included a range of herbicide applications at various stages of the crop growth (Table 1). The trials in 1982-83 and 1983-84 represent average weed infestation levels for crop rota-

Table 1. Site and treatment details for a series of experiments on the effect of herbicide application in autumn and or spring on yield of winter wheat in the Netherlands. Wheat development stage at the time of spring application is indicated after Zadoks et al. (1974).

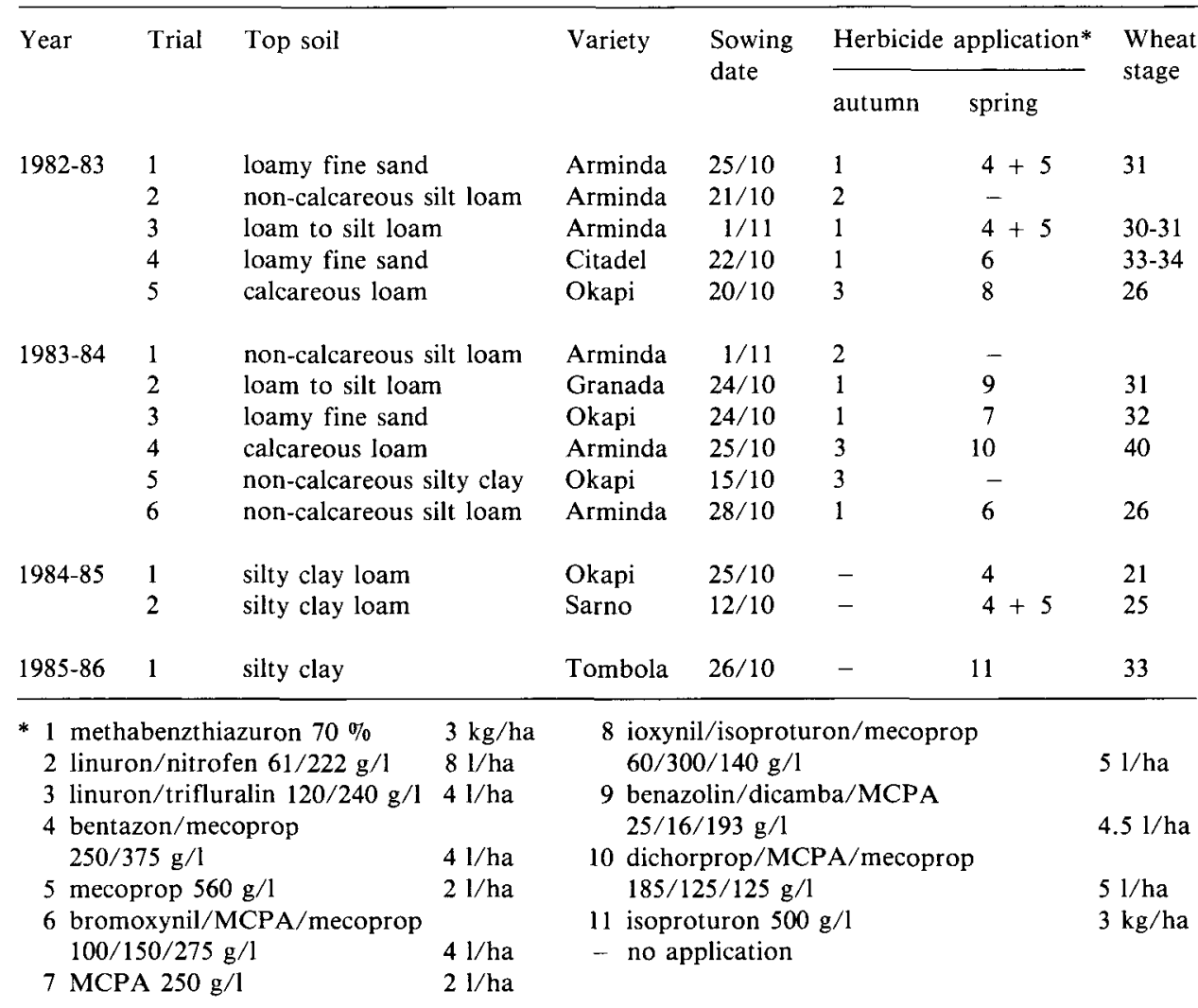


tions with cereals, potatoes and sugar beet (H. F. M. Aarts, pers. comm.). The sites of the trials in 1984-85 and 1985-86 were selected for an expected high density of weeds (e.g. Matricaria chamomilla, Alopecurus myosuroides). Each experiment was of a randomnized block design with four replicates. At most sites the individual plots measured $40 \mathrm{~m} \times 6 \mathrm{~m}$. Row distances of winter wheat varied between 0.12 and $0.25 \mathrm{~m}$, mostly between 0.18 and $0.20 \mathrm{~m}$. The pre-emergence herbicides were sprayed within two days after sowing. Each experiment contained a control treatment (no herbicide).

In 1983 the following characteristics were measured at monthly intervals from March until August in 5-12 quadrats (ranging from 0.10 to $0.25 \mathrm{~m}^{2}$ in each plot: the number of wheat plants (from June the number of culms) and their mean height, leaf area and above-ground dry weight; the number of seedlings per weed species and the mean plant height and developmental stage (vegetative phase, flowering, seed maturing) for each species. In August the total dry weight of the weeds was measured. The specific leaf area and patterns of biomass partitioning of the most frequently occurring weed species were determined at least twice in the growing season. In 1983-1986, final grain yields (at $84 \%$ dry matter) were determined in one quadrat (ranging from 17.25 to $45 \mathrm{~m}^{2}$ ) per plot, using a combine to harvest the wheat. Differences in grain yields between herbicide treatments and unsprayed treatments were tested by analysis of variance.

\section{Simulation analyses}

The growth of the wheat crop and weeds was simulated with a mechanistic model of competition for light and water. This model calculates the daily growth rates of the species in the canopy by distributing the factors that promote and limit growth (i.e. light and water) over the species. The dry matter produced is distributed over the plant organs in accordance with the developmental stage of crop and weeds. Leaf area development early in the growing season is simulated on the basis of an experimentally determined temperature-dependent relative growth rate of leaf area. When the canopy closes, leaf area development is calculated from the dry matter increment of the leaves and an experimentally determined specific leaf area, which is a function of the developmental stage. Spitters \& Aerts (1983), Kropff (1988), and Spitters (1989) supplied a detailed presentation of the model's structure and its performance. The basic model structure has been validated for weed competition in sugar beet and maize (Spitters \& Aerts, 1983; Spitters, 1984; Kropff et al., 1984; Kropff 1988).

The following model inputs were obtained for the five experiments done during 1982-83: daily weather data from nearby stations (maximum and minimum temperature, total global radiation, rainfall, humidity and wind speed), dates of crop and weed emergence, plant density and height. For the weeds, specific leaf area and pattern of biomass partitioning over stems, leaves and reproductive organs were derived from the data measured in the experimental plots, whereas for wheat the values of the parameters of these and other physiological characteristics were obtained from Spitters et al. (1989). Data on the permanent wilting point of the soils, field 
capacity and rooting depth were derived from observations at the study sites in later years.

In the quadrats used in these experiments the frequently occurring weeds included Capsella bursa-pastoris, Poa annua, Stellaria media, Polygonum spp., and Galium aparine. Standard errors of simulated data were computed on the basis of simulated effects for the observed weed densities in the different blocks.

\section{Results}

The fourteen field experiments varied in many aspects (e.g. in soil type, weather, weed composition and density, and other farm-specific characteristics). In the experiments in the growing seasons of 1982-83 and 1983-84 the effects of herbicides applied in autumn or spring on grain yield of winter wheat were found to be marginally significant in only two cases (Table 2). The dry matter production of weeds was not related to the observed yield losses, defined as (yield herbicide - yield $_{\text {no herbicide }}$ / yield $_{\text {herbicide }} \times 100 \%$ (Table 2 ). In a regression analysis within sites (1982-83) of total dry matter production of wheat against that of weeds, no relationship was found (data not presented).

Table 2. Effects of herbicide applications either as pre-emergence in autumn or as crop treatment in spring on grain yield $\left(\mathrm{kg} \mathrm{ha}^{-1}\right)$ of winter wheat. Yield loss had been defined as (yield herbicide -yield $_{\text {no herbi- }}$ cide $) /$ yield herbicide $\times 100 \%$. The total dry matter production of weeds is indicated for harvest time of the wheat. Significant and marginally significant effects of treatment on seed yield have been indicated between brackets.

\begin{tabular}{|c|c|c|c|c|c|c|}
\hline \multirow[t]{2}{*}{ Year } & \multirow[t]{2}{*}{ Trial } & \multicolumn{2}{|c|}{ Yield loss $(\%)$} & \multicolumn{3}{|c|}{ Dry matter production weeds ( $\mathrm{kg} \mathrm{ha}-1)$} \\
\hline & & $\begin{array}{l}\text { autumn } \\
\text { application }\end{array}$ & $\begin{array}{l}\text { spring } \\
\text { application }\end{array}$ & no herbicides & $\begin{array}{l}\text { autumn } \\
\text { application }\end{array}$ & $\begin{array}{l}\text { spring } \\
\text { application }\end{array}$ \\
\hline \multirow[t]{5}{*}{$1982-83$} & 1 & 8.7 & 7.6 & 645 & 146 & 425 \\
\hline & 2 & -2.9 & $-{ }^{*}$ & 336 & 146 & - \\
\hline & 3 & 1.6 & 0.9 & 1164 & 1 & - \\
\hline & 4 & -1.9 & 1.0 & 58 & 11 & - \\
\hline & 5 & 5.1 & $4.2(P<0.07)$ & 124 & 80 & - \\
\hline \multirow[t]{6}{*}{ 1983-84 } & 1 & -0.1 & - & 75 & 91 & - \\
\hline & 2 & -0.3 & -0.7 & 117 & 3 & - \\
\hline & 3 & -0.1 & 0.0 & 102 & 39 & - \\
\hline & 4 & -1.3 & -2.4 & 156 & 51 & - \\
\hline & 5 & 4.4 & - & 212 & 39 & -. \\
\hline & 6 & 2.8 & $4.7(P<0.06)$ & 198 & 17 & - \\
\hline \multirow[t]{2}{*}{ 1984-85 } & 1 & - & $39.9(P<0.01)$ & 838 & - & 183 \\
\hline & 2 & - & 4.8 & 135 & - & 2 \\
\hline $1985-86$ & 1 & - & $35.7(P<0.06)$ & 2882 & - & 784 \\
\hline
\end{tabular}

$*-=$ no observation. 
Table 3. Comparison of observed and simulated yield loss (total above-ground diry matter production) of winter wheat in five trials (1982-83). Yield loss has been defined as (yield herbicide - yield $_{\text {no herbicide }}$ )/ yield $_{\text {herbicide }} \times 100 \%$. Standard errors (between brackets) have been computed over four blocks.

\begin{tabular}{|c|c|c|}
\hline \multirow[t]{2}{*}{ Trial } & \multicolumn{2}{|l|}{ Yield loss $(\%)$} \\
\hline & observed & simulated \\
\hline 1 & $-9.7(0.8)$ & $5.4(1.3)$ \\
\hline 2 & $-11.1(13.6)$ & $0.0(0.0)$ \\
\hline 3 & $-1.4(3.1)$ & $0.0(0.0)$ \\
\hline 4 & $1.9(2.6)$ & $0.0(0.0)$ \\
\hline 5 & $8.3(6.7)$ & $5.8(1.7)$ \\
\hline
\end{tabular}

In the 1984-85 and 1985-86 trials one significant and one marginally significant effect of herbicide treatment on wheat yield were found (Table 2). The data from these last two harvest years demonstrated that at rather extreme high weed densities of particular weed species (Matricaria chamomilla, Alopecurus myosuroides) omission of weed control may result in a seriously decreased crop yield.

Simulated yield losses are compared with observed yield losses (1982-83) in Table 3. Dynamic simulation resulted in relatively small effects of weeds on wheat yield, as was observed in the experiments. However, within the range of yield losses, the simulated and observed values were clearly not correlated. The standard errors (over blocks) were considerably smaller for the simulated yield losses than for the observed losses.

The effect of time of emergence and maximum height of the annual broad-leaved weeds on yield loss was analysed with the model using the weed species characteristics of Chenopodium album and average daily weather data for Wageningen (Table 4). Simulated yield loss appeared to be strongly affected by date of emergence of the weeds. The simulated competition effect of weeds that emerge in autumn was markedly higher than that of weeds that emerge in spring (31 March). Maximum height of the weeds also strongly influenced yield loss. Simulations with weeds that emerged in autumn at a density of 100 plants $\mathrm{m}^{-2}$ showed that weeds attaining a final height of $1 \mathrm{~m}$ (about the final height of wheat) could reduce the yield by almost $20 \%$, whereas 'autumn' weeds with a maximum height of $25 \mathrm{~cm}$ caused only $4 \%$

Table 4. Simulated yield loss of winter wheat at different times of emergence and maximum heights of weeds. Weed density was 100 plants $\mathrm{m}^{-2}$. See text for other parameter values.

\begin{tabular}{lll}
\hline $\begin{array}{l}\text { Maximum height } \\
\text { of weeds }(\mathrm{cm})\end{array}$ & \multicolumn{2}{l}{ Simulated yield loss $(\%)$} \\
\cline { 2 - 3 } & weeds emerged in autumn & weeds emerged in spring \\
25 & 4.3 & 0.1 \\
50 & 6.1 & 0.1 \\
100 & 18.6 & 0.2 \\
\hline
\end{tabular}


yield loss (Table 4). Weeds that emerge in spring had little effects, therefore the effects of the maximum height of these weeds on crop yield were only marginal.

Finally, the relationship between the specific leaf area of weeds (emerged in autumn) and yield loss were analysed with the model. At a weed density of 100 plants $\mathrm{m}^{-2}$ the simulated yield losses were $5.9 \%, 6.1 \%$ and $6.5 \%$ for specific leaf areas of $0.002,0.003$ and $0.004 \mathrm{~m}^{2} \mathrm{~kg}^{-1}$, respectively.

\section{Discussion}

The two sets of field experiments of 1982-83 and 1983-84 match the average growing conditions of winter wheat in the Netherlands. Both the experimental and the simulated results show that the application of herbicides in this crop is only rarely justified on the basis of a decreased yield in the current year. These results agree with results found in the United Kingdom (see Introduction). In our research dynamic simulation using input variables measured in separate plots within five trials resulted in similar small effects of weeds on winter wheat. Subsequent analyses by means of this simulation model demonstrated that some plant characteristics have specific effects on final wheat yield. The maximum height of annual dicot weeds that emerge in autumn is expected to considerably influence the yield loss caused by weed competition. The simulated crop yield appears to be hardly sensitive to the specific leaf area of weeds (cf. Kropff, 1988).

Simulation analyses also demonstrated that season of weed emergence has an important effect on final crop yield. In contrast to weeds that emerge in autumn, weeds emerging in spring may hardly affect wheat yield. This simulation result might explain the similar effects of autumn and spring weed control in winter wheat (Orson 1982, Wilson 1982, Table 2). After herbicide treatment in autumn, weeds that emerge in (late) spring in the nearly closed winter wheat stand, generally lack competiveness to reduce crop yield. Therefore, successful autumn and spring treatments would not result in different crop yields. The results obtained by Cousens et al. (1987) and Kropff (1988) also demonstrated that the relative time of emergence of weeds had a major effect on the yields of cereals and sugar beet.

Although the dynamic simulation model helps to elucidate and to explain variation in yield loss due to weeds, additional research might increase the usefulness of this model for studies of crop/weed interaction and for use in future advisory systems. First, the negative effects of herbicides on crop growth and development have to be incorporated in the model. However, the necessary quantitative data are scarce. Secondly, few data are available to characterize patterns of biomass allocation over the roots, stems, leaves and reproductive organs of the weed species. These allocation data are markedly influenced by environmental factors and are also subject to ecotypic differentiation (e.g. Lotz \& Blom 1986), and therefore further analyses of the morphogenetics of weeds are needed so that more realistic values can be obtained for these parameters. Finally, input of more detailed data on weed demography might increase the reliability of the simulations. In our simulation analysis all the plants of a weed species are assumed to emerge on the date on which the first plants are observed in a plot. This approach probably gives a conservative 
(relatively early) pattern of weed emergence and therefore overestimates the competiveness of the weeds. Additional data on the population dynamics of weeds are also needed to relate weed density in the current year to future weed densities, since in weed management systems any decrease in the intensity of weed control should not only be directed to final crop yield in the current year, but also to the intensity of weed control and yields in subsequent year.

The present results, which demonstrate that herbicides have no or only small effects on wheat yield, probably strongly depend on the fact that sugar beet and potatoes are included in Dutch crop rotation systems. In these relatively highly profitable crops the current system of weed management is intensive. Because the crop canopy is open until the second half of June, weeds germinating in spring are effectively controlled. Moreover, in these dicot crops any increase in the population of monocot weeds can be prevented by using highly specific herbicides.

\section{Acknowledgements}

The authors gratefully acknowledge H. F. M. Aarts, K. van Gerwen, W. de Groot and C. J. T. Spitters ( $\dagger$ ) for providing unpublished experimental data and G. W. Cussans, J. Goudriaan, M. Hoogerkamp, R. Rabbinge, J. H. J. Spiertz and C. J. T. Spitters $(\dagger)$ for comments on earlier drafts of this article.

\section{References}

Cousens, R., P. Brain, J. T. O'Donovan \& P. A. O'Sullivan, 1987. The use of biologically realistic equations to describe the effects of weed density and relative time of emergence on crop yield. Weed Science 35: 720-725.

Evans, S. A. \& J. J. Harvey, 1978. Annual broad-leaved weed control in winter wheat: autumn and spring treatments compared. Proceedings 1978 British Crop Protection Conference - Weeds, p. $41-48$.

Kropff, M. J., 1988. Modelling the effects of weeds on crop production. Weed Research 28: 465-471.

Kropff, M. J., F. J. H. Vossen, C. J. T. Spitters \& W. de Groot, 1984. Competition between a maize crop and a natural population of Echinochloa crus-galli (L.) P.B. Netherlands Journal of Agricultural Science 32: 324-327.

Lotz, L. A. P. \& C. W. P. M. Blom, 1986. Plasticity in life-history traits of Plantago major L. ssp. pleiosperma Pilger. Oecologia (Berlin) 69: 25-30.

Orson, J. H., 1980. Annual broad-leaved weed control in winter wheat and winter barley. Autumn and spring treatments compared. Proceedings 1980 British Crop Protection Conference - Weeds, p. 251-258.

Orson, J. H., 1982. Annual broad-leaved weed control in winter wheat and winter barley, autumn and spring treatments compared. Aspects of Applied Biology 1: 43-51.

Spitters, C. J. T., 1984. A simple simulation model for crop-weed competition. Proceedings 7 th International Symposium on Weed Biology, Ecology and Systematics, Paris, France, p. 355-366.

Spitters, C. J. T., 1989. Weeds: population dynamics, germination and competition. In: R. Rabbinge, S. A. Ward \& H. H. van Laar (Eds) Simulation and systems management in crop protection, p. 182216. Simulation Monographs, Pudoc, Wageningen.

Spitters, C. J. T. \& R. Aerts, 1983. Simulation of competition for light and water in crop-weed associations. Aspects of Applied Biology 4: 467-483.

Spitters, C. J. T., H. van Keulen \& D. W. G. van Kraailingen, 1989. A simple and universal crop growth simulator: SUCROS87. In: R. Rabbinge, S. A. Ward \& H. H. van Laar (Eds) Simulation and systems management in crop protection, p. 147-181. Simulation Monographs, Pudoc, Wageningen. 
L. A. P. LOTZ, M. J. KROPFF AND R. M. W. GROENEVELD

Wilson, B. J., 1982. The yield response of winter cereals to autumn and spring control of broad-leaved weeds. Aspects of Applied Biology 1: 53-61.

Zadoks, J. C., T. T. Chang \& C. F. Konzak, 1974. A decimal code for growth stages of cereals. Weed Research 14: 415-421. 